\title{
Modernity in architecture as the synergy of ideas, tradition and nature - opera in Bialystok
}

\author{
Andrzej Tokajuk \\ https://orcid.org/0000-0002-7532-6414 \\ a.tokajuk@pb.edu.pl \\ Faculty of Architecture, Bialystok University of Technology
}

\begin{abstract}
The author of the article the is analysing the problem of modernity in architecture on the example of the concept of Podlasie Opera and Philharmonic in Bialystok - one of the most interesting project of contemporary architecture in Poland. It shows a kind of new way in creating modern public building not only in Poland but also in Europe. That means a special synergy of ideas, tradition, technology and nature in architecture - the sophisticated way to achieve modernity in contemporary design. The project was based on three ideas - which concerns mainly to local context (religious hills, Orthodox and Jewish cemeteries), tradition of antique architecture and saint places of Israel and the city centre of Bialystok. Significant role in the project plays the greenery - plants on elevations, poles, roofs, introduced on a few different levels. This ecological aspect refers to the very important tendency of $21^{\text {st }}$ century - sustainable architecture. The complex was designed by studio of Marek Budzynski Architect and was constructed during 2005-2012. We can define the project as the synergy and synthesis of the tradition with the modernity, integration of architecture, culture, technology and the landscape.
\end{abstract}

Keywords: modernity, architecture, synergy, opera

\section{Introduction}

In contemporary architecture we can find many concepts of modernity [Heynen 1999]. In $20^{\text {th }}$ century the term of modernity was identified with modernism movement and its paradigm of form and space. Now, in $21^{\text {st }}$ century we refer modernity in architecture also to other aspects: the original forms, modern or new materials, innovative constructions [Gunel M.H., Ilgin H.E. 2014], implementations of old materials or looking for different relations of old details and elements in new projects, parametric design [Asanowicz 2017] sustainability, - all these we can notice in some designs of high-rise buildings, public buildings, industrial designs, one family houses, residential buildings, etc. [Mozas, Per 2004].

In Poland a few original architectural projects of concert halls, music centres, projects where music meets architecture were designed and built in the beginning of $21^{\text {st }}$ century. Some of them are sophisticated, very modern in many aspects and became famous, e.g. Philharmonic Hall in Szczecin designed by Spanish architects Estudio Barozzi Veiga - is the winner of the 2015 EU Prize for Contemporary Architecture - Mies van der Rohe Award. The design was influenced by the surrounding context and buildings, specifically by the "verticality of the city's residential buildings, by the monumentality of the upright ornaments of its neo-Gothic churches and the heavy volumes of its Classicist buildings, by the towers that dot its entire skyline and the cranes of its port," according the architects. ${ }^{1}$ Other projects also represent very interesting architecture - e.g. the building of National Symphonic Orchestra of Polish Radio in Katowice, arch. Tomasz Konior Studio (with the auditorium 
for 2000 persons), the building of National Music Forum in Wroclaw, arch. Kurylowicz \& Associates Office, Cultural-Congress Center in Torun, arch. Fernando Menis and Podlasie Opera and Philharmonic in Bialystok, arch. Marek Budzynski Office. All mentioned above projects created modern architecture, but the last example was selected as the object of analysis in the article - because of its specific aspect of modernity in contemporary architecture - based on sophisticated synergy of ideas, tradition, technology and nature.

Podlasie Opera and Philharmonic in Bialystok was created as the part of the project called European Centre for the Arts. It was located in the place of the degraded amphitheatre and became one of the most interesting public building realized in Poland in the beginning of the $21^{\text {st }}$ century. The new building of the Podlasie Opera was being constructed during 2005-2012. The general designer of the whole complex was studio of Marek Budzynski Architect. A context of the location of the new building is very important - the city centre of Bialystok. The first project contained of the building of the opera, the multi-screen cinema and an underground parking. The realization of the project took 8 years, with some breaks, it was supported by the financial means from the EU. The main authors are the architects: Marek Budzyński, Krystyna Ilmurzyńska, Zbigniew Badowski; in the process of design there were involved several other persons: Maciej Wojciechowski - designer of theatre engineering, Jan Dodacki - acustic engineer, Teresa Murak - sculptor, Dominik Wdowski - sculptor, Rafał Olbiński - painter, Tomasz Urbanowicz - artistic glass designer and others. ${ }^{2}$ The author of this article has taken the trial of using a kind of parametrical methodology, analyzing such elements as: urban composition, context, architectural concept and sustainable aspects of the new Podlasie Opera. This means the way to solve a complex problem to get some answers (concerning aspects mentioned above) and it will help to obtain clear, synthetic results in the end of the research (according Ch. Jencks definition) [Jencks 1987].

\section{The synergy of context and cultures ideas - urban space}

A context of the location of the new building of opera is very important - the religious hill and the small Orthodox Church of St. Maria Magdalena's, ancient cemeteries: Orthodox and Jewish, New opera interacts and makes spatial integration also with Dolls' Theatre (arch. Klyszewski, Mokrzycki, Wierzbicki, built in 1975); socrealistic urban composition with the axis of Sklodowska street which ends Philharmonic Hall (arch. Drewnowska, built in 1976) and contemporary Central Park established after the war, with the Monument of the Podlasie Heros huge columns (sculptors Zbichorski, Chmielewski), erected in 1975. This district in the centre of Bialystok was characterized by chaotic space, the process of making order started here a few years ago and now it is pointed as the new city centre. The location of the opera gave the chance to make spatial order in this district, where some services, housing and university buildings were dominated so far. The project in general was based on 3 ideas - the idea of Hope and Co-existing, the idea of the axis of the Podlasie Art, and the idea of the Tradition. The idea of Hope and Co-existing means the spatial dialogue of the Church of St. Roch's and green opera, University Square, memories of cemeteries. The memory of saint places and saint hill creatures certain spatial and emotional relations. The temple of the Arts connects all buildings and urban schemes mentioned above.

An urban plan idea appears from it - connecting the existing city centre of Bialystok with the created new city centre - Rynek Sienny space, thanks to the Odessa street as the axis of the Podlasie Arts. The main aim of opera spatial disposition is the connection new building with the landscape, surroundings and partly hide him in the ground. Other rules of spatial compositions are making view frames for pedestrian ways, streets and micro-interiors, which we can call as urban identification signs of the project of M. Budzynski. Such identification signs are small amphitheatre, roof terrace joined with open stairways along Odeska street and the space of foyer. The site surfice is 21829 sq.m.; the surfice of the contruction - 6303 sq.m.; useble surfice inside - 12978 sq.m.; total surfice of the building - 16109 sq.m.; volume - 108868 cubic m. ${ }^{3}$ The investor was Local Government of Podlasie Region of Poland. 

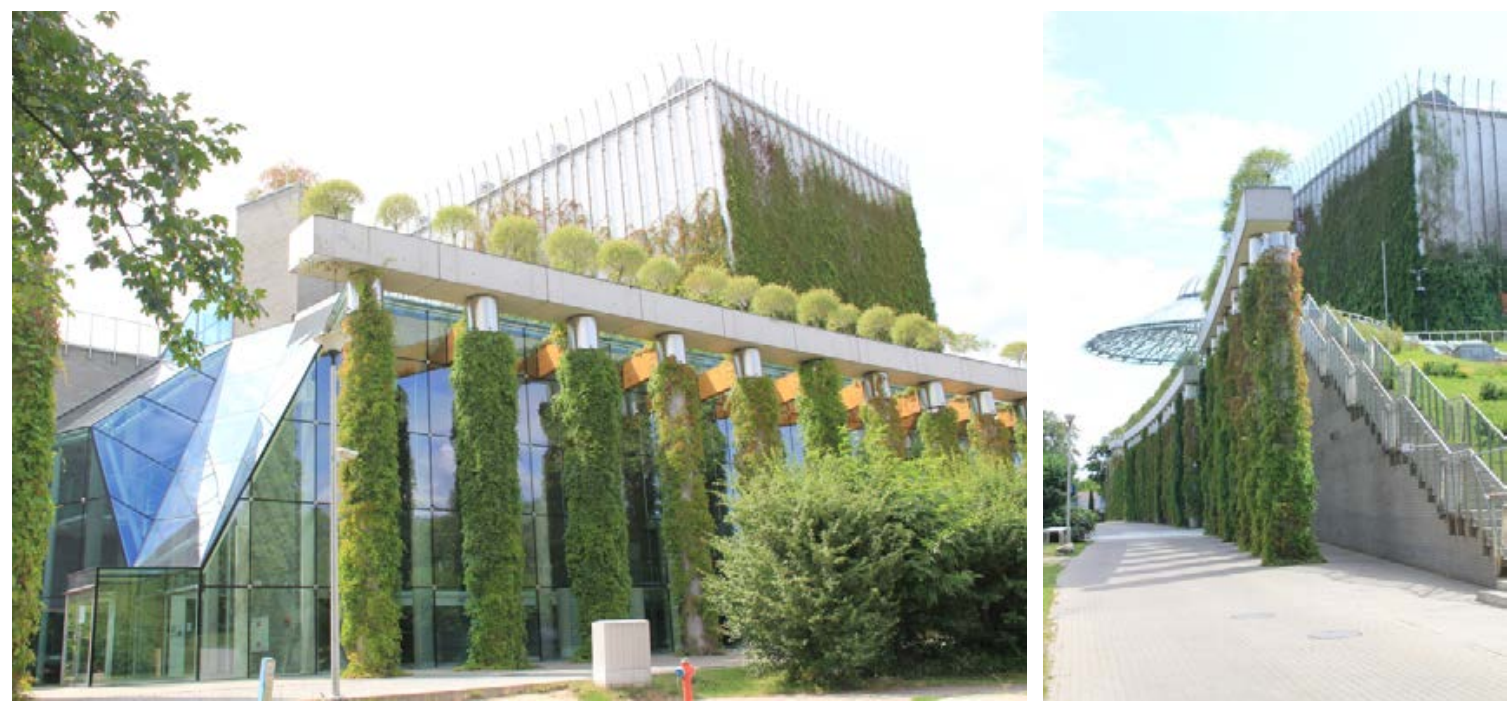

Fig. 1. A, B. The Opera and Philharmonic in Bialystok - the main view and the view along the axis of Podlasie Art. Photo: Andrzej Tokajuk.

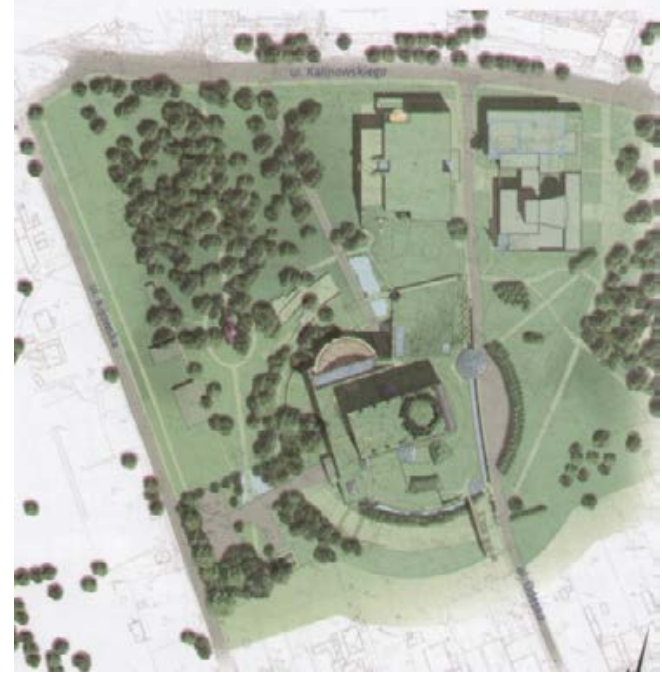

Fig. 2. The Opera and Philharmonic - urban concept and context. Source: Photo from exibition of projects competition by Andrzej Tokajuk.

\section{The synergy of tradition, materials and art - architectural space}

The idea of Tradition concerns the architectural concept and means inspiration of the old, ancient saint hills, buildings of Egypt, buildings of the Holy Places of Israel. The idea of opera project means the creation of a kind of union between saint places of Orthodox and Jewish cemeteries and the saint hill of St. Maria Magdalena's and connect them with the temple of art. The Park permeates the opera. We can see the tendency of citation of traditional forms - for instance elements of ancient Greek style in the colonnade and amphitheatre - all this makes the idea of Tradition. Also the integration of architecture and landscape (by location of the building partly inside the hill slope), composition of the main entrance - all these belong to the catalogue of traditional solutions. The idea of Tradition also refers to interior design concept of the opera and means, according the architect-designer, some reflections and citations of Secession, Art-Deco and High-tech [Stiasny, Bujas 2012]. The structure of the plan (opera layout) follows the function - in the zone for the audience we can find foyer and main auditorium; then we can find the zone of the stage, technical support space, rehearsal hall (chamber 
hall). The foyer of the opera is very important space - it was designed as the pedestrian covered passage, where small concerts, exhibitions and other events may take place. Fully glassed wall of the foyer gives the opening to the east Central Park and acts as the accessible public space - the continuation of the Park. The symbolic border between these two spaces is the colonnade with growing plants. Inside foyer there are some elements - architectural details which play the big aesthetic role - concrete columns and hanging stairs, piers and bridges made with glass and steel. The roof is going up and all these things direct the foyer - in real and symbolic ways - up, towards the light. The axis of the main entrance leads through the "Odessa stairs" on the next level where we can find entrances to the main auditorium and new amphitheatre. Stone stairs symbolize the road upstairs from the "street art" (pop art) to the "high art" (paintings, sculpture, classical music). The intention of the architect was the integration of fine arts with architecture in the interior. This tendency was often seen in Poland in 70. last century, but later it disappeared. Marek Budzynski invited some artists to collaborate and they did significant job inside the building. In the foyer there are impressive details made with artistic glass by Tomasz Urbanowicz. The most interesting are the glass panels with décor of notes coming from big composers; panels were made using hand made forms (1,50 meters by 1,80 meters, more than $300 \mathrm{~kg}$ weight). The idea was to show the soul and the beauty in the glass, not just the graffic pattern. The details have the rich surface, with varied colours. In similar way the capitals of the columns were shaped. The glass elements gave very interesting composition with architectural concrete of walls and columns. The colours and materials in other rooms of opera create special atmosphere inside. The rehearsal hall - chamber hall - was designed using the idea of black box, fully in black colour with some steal technical equipment only, helping to arrange this space to different kinds of events. Main auditorium was designed using the principle of joining the opposites. It was the trial to combine the atmosphere of interior historical opera with the contemporary flexible multifunctionality; combine traditional plan of auditorium with the modern concepts of auditorium, acustics and visuality. The auditorium contains 772 main places and 964 places when some places are situated on the stage. ${ }^{4}$ There have been established conditions for different kinds of spectacles - opera, symphony concert, symphony concert with the shell, oratorium concert, a classical theatre, a theatre from reduced by the moat, theatre-in-the-round, theatre musical/ballet, conference, etc. Materials and colours solution are the result of the concept referring to the Secession, Art-Deco and High-Tech (integration of architecture, paintings, sculpture, hand-made art). The concrete walls were painted dark blue, chairs are made with wood painted dark green with red soft material of seats. The detail of balustrades - musical staff is very characteristic. In upper part of the auditorium some sculptures were located by the designers - as humanistic element to technical interior. Concrete casts of musicians, singers, dancers come from famous operas, they play the role of decorative function and also they disperse sounds. A large stage is filling the whole of dimensions with $16 \times 16.5$ meters flat with the large curtain - the painting, stage devices and the acoustic ceiling with the possibility of changeable shape and height.

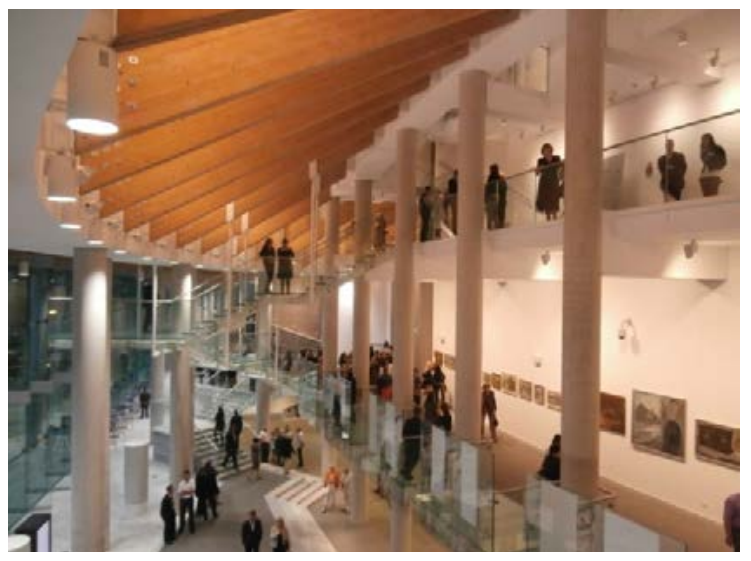

Fig. 3. The Opera and Philharmonic in Bialystok - foyer view. Photo: Andrzej Tokajuk.

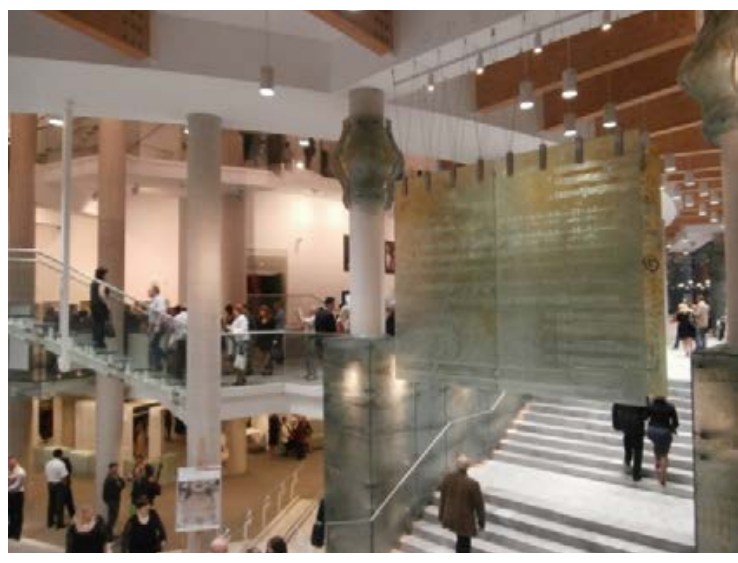

Fig. 4. The Opera and Philharmonic in Bialystok - interior details. Photo: Andrzej Tokajuk. 


\section{The synergy of nature and architecture}

In the project of the new opera we can see many ecological aspects: omnipresent greenery - climbing plants on elevations, poles, roofs, introduced on a few different levels. It is a kind of synthesis nature and culture using architectural art. The greenery was designed on a few levels. This way of greenery implementation refers to the sustainability paradigm in designing contemporary architecture [Uffelen 2017]. On the ground level we can see the row of hawthorns, which separates the front of the building and the Central Park; also some water lakes with rainwater and fish from the amphitheatre side. Next level of plants form gardens with natural plants. They create fantastic natural meadow with flowers, grass, forming on the green slope, where part of the building was hidden (kind of recreation zone between park and opera). On the same level there are also climbing plants on grids surrounding columns and growing on the wall outside the technical elevation (west). Next green level - it is the garden situated on the roof of the foyer, where we get from a few directions using cascade stairs. There are some paths around main form - box of the auditorium and stage. On the same there are trees located on the colonnade in front of the main entrance. Another green level creates climbing plants on the concrete walls of opera forming big box over the stage and auditorium. Last green level was designed as a garden on the roof over the stage - in form of natural meadow, with the access using lift or curved pair of stairs. In addition, we can find modern totemic sculpture of Teresa Murak - the head of composer, made with cast iron.

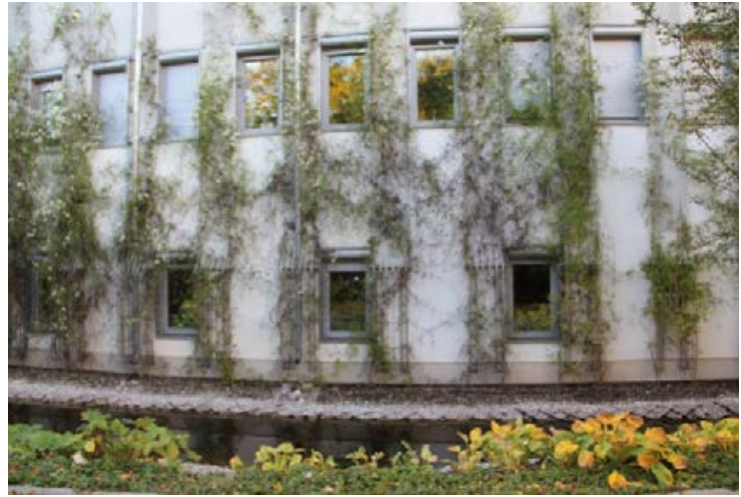

Fig. 5. The Opera and Philharmonic in Bialystok - plants growing on the main hall. Photo: Andrzej Tokajuk.

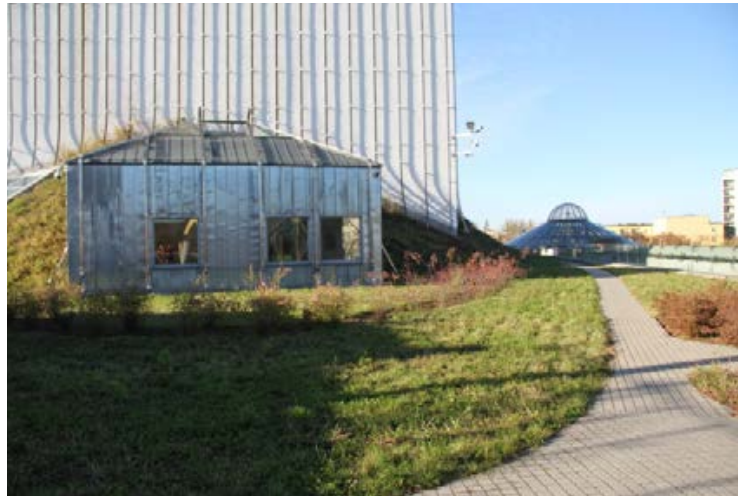

Fig. 6. The Opera and Philharmonic in Bialystok - roof garden on the second level. Photo: Andrzej Tokajuk.

\section{Results and discussions}

Based on conducted analyses, we can say the thesis, that the Podlasie Opera and Philharmonic designed by the office of Marek Budzynski Architect is the example of new tendency in the architecture of $21^{\text {st }}$ century. We can call it New Romanticism or Modernist Romanticism [Bujas 2012]. We can conclude from the analysis above that it possible to situate the style of the new building between the classical postmodernism (the individualistic postmodernism) and minimalism. The whole spatial concept is based on the deep philosophy connecting the tradition with the present times. Architectural solution is based on the pure concrete, glass and green plants and minimalistic form of the main hall. Interior project plays with concrete, glass details, wooden beams and roof elements, sculptures and white or black colours. So we can conclude, that architectural concrete, glass and green plants play the main role in architecture of the object. Pure - "brut" concrete we can clearly see in the forms of the main concert hall outside and the open amphitheatre located in the back. In the building of the opera can find some connections with the brutalism architecture (for instance with aspect of using the texture of concrete). This trend was developed in Poland in 60. and 70. of twentieth century - such examples of brutalism we can see in several project from Cracov realized that times [Niebrzydowski 2015].

On the other side we must admit, that there are not any details in architecture and interior taken from local culture of Podlasie region, corresponding with local context and history of the town. The form of the Opera 
dominates the whole area because of its huge scale, also over the cameral orthodox Church of St. Maria Magdalena on the hill - it gives new spatial, urban proportions, which are not good (in spite of intentions of the designers). Moreover the investor (local authorities) did not build undergrounds parking places, mainly because of financial conditions. They must do it in the future, now it makes a communication problem. The plants on the main hall are growing very slowly in the Polish difficult climate; we do not know how long it will take until the elevations of the building will look similar to the project visualizations. The huge concrete box looks good only from one side - the front, from other sides the simple, concrete form is strange and ugly. The concept of keeping natural way of the green meadows on many levels of the building could make some troubles after some time (without every year cutting and proper maintaining) - the opera administration probably will must change some plants which generates a lot of costs in the future. There is also the question, if metal grids for plants are not too hot for climbing plants in summer time.
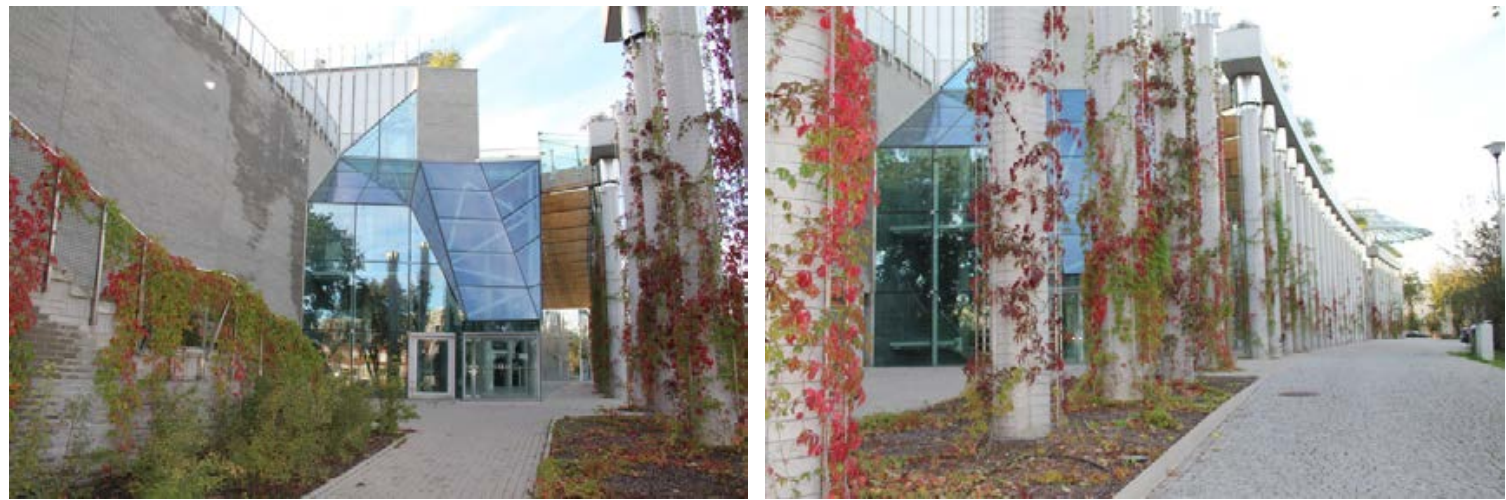

Fig. 7. A, B. The Opera and Philharmonic in Bialystok - main entrance facade; materials: glass, wood and concrete. Photo: Andrzej Tokajuk.

\section{Conclusions}

The project of Podlasie Opera and Philharmonic is very original, very conceptual and based on ideas, mixing the past, the present and the future. But it also provokes the discussion. Most problems mentioned in discussion part of this text are controversial, the project is full of complexity, contradictions, integrating architecture, philosophy and nature. Also we can find the synthesis of opposites - synthesis of the tradition with the modernity, row of columns with simple cubic form and Greek amphitheatre, green plants on the roofs, the project is the trial to integrate Jewish and Orthodox cemeteries, making the spatial composition of Odeska and Operowa Streets with new forms like "saint places". The integration of the architecture and fine arts in interior and the architecture and landscape outside became the main motives of the whole concept.

Finally we can say, that opera in Bialystok is very important example of the connection culture and nature using the architectural art - the building has become the new element of identity of Bialystok. The result of synergy of ideas, tradition, technology and nature incorporated in the project of opera we can find as the modernity of architecture of $21^{\text {st }}$ century.

The research was carried out in the frame of scientific project No. S/WA/2/2016 at the Bialystok University of Technology, Faculty of Architecture and financed from subvention sources by Polish Ministry of Science and Higher Education. 


\section{References}

[1] Asanowicz A., 2017, "Parametric design. Tool, medium or new paradigm?", Proceedings of the $35^{\text {th }}$ International Conference on Education and Research in Computer Aided Architectural Design in Europe, Rome, p. 379-386.

[2] Bujas P., 2012, „Od postmodernizmu do nowego romatyzmu“, Architektura-murator, Warszawa, nr 11, ISSN: 1232-6372 p. 66-69.

[3] Gunel M.H., Ilgin H.E., 2014, "Tall Buildings. Structural Systems and Aerodynamic Form”, Routledge, Taylor \& Francis Group, New York.

[4] Heynen H., 1999, "Architecture and modernity: a critique”, MIT Press Massachusets, USA, p. 8-25.

[5] Jencks Ch., 1987, „Architektura postmodernistyczna”, Polish Edition, Arkady, Warszawa.

[6] Mozas J., Per A.F., 2004, New collective housing - density, a+t ediciones, Vitoria-Gasteiz, p. 204-290.

[7] Niebrzydowski W., 2015, "Brutalism in Poland on the Example of the Architecture of Krakow”, Journal of Sustainable Architecture and Civil Engineering, 2015 / nr 1 (10), Kaunas University of Technology - Faculty of Civil Engineering and Architecture, pp. 40-49.

[8] Stiasny G., Bujas P., 2012, „Światopogląd wyrażony w formie”, Architektura-murator, Warszawa, nr 11, ISSN: 1232-6372, p. 60-64.

[9] Uffelen v. Ch., 2017, Green, greener, greenest. Facades, roofs, indoors., Braun Publishing AG, Berlin, p. 6-70.

[10] https://www.archdaily.com/628924/barozzi-veiga-s-philharmonic-hall-szczecin-receives-2015-eu-prize-for-contemporary-architecture-nil-mies-van-der-rohe-award, accessed 29 ${ }^{\text {th }}$ June 2018.

[11] http://opera.bialystok.pl/en/institution-en.html, accessed 17 th May 2017. 